\title{
Pre-drilling and self-drilling pins screw-bone fixation stress interaction analysis induced by uniaxial compression loading
}

\author{
Lim Pei Chee ${ }^{a,}{ }^{*}$, Ruslizam Bin Daud ${ }^{a}$, Shah Fenner Khan Bin Mohamad Khan ${ }^{a}$, Nurul Alia Md \\ Zain $^{\mathrm{b}}$, Shamini Abdullah ${ }^{\mathrm{b}}$ and Yazid Bajuri ${ }^{\mathrm{c}}$
}

a School of Mechatronics Engineering, Universiti Malaysia Perlis (UniMAP), Pauh Putra Campus, 02600 Arau, Perlis, Malaysia

${ }^{b}$ Institute of Mathematics and Centre for International Languages, Pauh Putra Campus, 02600 Arau, Perlis, Malaysia

c UKM Medical Centre,Department Orthopaedics and Traumatology, Universiti Kebangsaan Malaysia, Kuala Lumpur, Malaysia

* Corresponding author: peichee@studentmail.unimap.edu.my

\section{Article history}

Received 25 January 2018

Revised 2 September 2018

Accepted 10 October 2018

Published Online 4 February 2019

\begin{abstract}
A newly designed Uniaxial external fixator which functions as a universal fixator in the application of all types of bone fractures is recently introduced by both Hospital Universiti Kebangsaan Malaysia (HUKM) and Universiti Malaysia Perlis (UniMAP). The Investigation is focused on identifying and measuring the performance in terms of strength or weakness of the fixator that is needed before the application to the human body. Hence, this research was conducted to determine the performance of Uniaxial external fixator which was based on geometry using different screw drilling techniques applied during an angled uniaxial compression load. A three-dimensional fixator-bone was constructed using different screw inserting techniques which was then converted into ANSYS v14.5 for the purposes of conducting a finite element analysis (FEA). Axial compressive loading with various degrees from 60 to $6300 \mathrm{~N}$ were applied to bone models to stimulate patient's daily activities while 10 to $100 \mathrm{~N}$ were applied to fixator models for the purposes of reviewing environmental loading to fixator-bone models. Findings revealed that maximum magnitude which caused deformation for predrilling and self-drilling models were located at the highest pin-bone interaction. Conversely, the maximum magnitude of the von Mises strain and stress was located at the lowest pin-bone interaction by omitting the existence of fixator for both Case 1 and 2 . There was no obvious difference in the comparison of both models in terms of deformation. However, predrilling models have higher strain and stress than self-drilling models. In sum, findings indicated that self-drilling models have better performance compared to the predrilling models.
\end{abstract}

Keywords: Three-dimensional, uniaxial external fixator, finite element analysis

@ 2019 Penerbit UTM Press. All rights reserved

\section{INTRODUCTION}

A bone fracture at the compact bone layer occurs when acute impact or stress is imposed on the bone during vehicle accidents, a fall from a substantial height, sporting injuries or industrial mishaps [1,2]. In such cases, the lower limb long bones may be broken more frequently in comparison to other bones [1]. In order to heal from the femoral shaft fractures, treatments such as surgery is required. Currently, internal and external fixation are the temporary treatments applied to any patient who experienced bone fracture in order to repair the femur bone fracture. Open reduction and internal fixation (ORIF) is a required surgical process for patients in order to install the fixation device while external fixation is a non-surgical treatment which fixes the simple bone fracture via installation of plaster casts, braces, splints and external fixator [1,3]. Bone fractures which are commonly treated by the internal fixations utilize wires, screws, pins, intramedullary (IM) nails or rods and bone plates. The basic goal of the fracture fixation is not only to stabilize or restore the fractured pieces of bone to the natural positions, but also enhance the natural healing process of the fractured bone into mobility within a specific period [3]. New bone tissue will start to form and the broken pieces will connect with one another after inserting the fixator [4]. However, this may take several weeks or months to heal, depending on the nature of the injury. Once the femur bone is healed and strong enough to handle the force of normal activities, the fixator will be removed from the patient [5].

There are several factors that may contribute to the instability of performance of the external fixators; specifically the design and material used for the external fixator. Standard pin, ring and hybrid fixator are three basic types of external fixators [3]. Standard uniplanar fixator is used for long bone fracture which excludes the proximal femur or humerus. This is done by installing an external rod that is connected by a string of pins that penetrates the near cortex and medullary canal and engages the far cortex without penetrating the muscle compartment. The ring fixator is normally made using thin wires under tension which are attached to a circular or semicircular rings and frames. The hybrid fixator on the other hand is the combination of standard and ring fixators which are used to treat and connect both the proximal and distal tibial fractures However, these traditional fixators are often inconvenient, uncomfortable and bulky [6]. Therefore, new designs of fixators such as Delta, Mitkovic and Unilateral external fixators have been introduced to overcome these problems.

A newly designed Uniaxial external fixator which functions as a universal fixator in the application of all types of bone fractures is recently introduced by both Hospital Universiti Kebangsaan Malaysia 
(HUKM) and Universiti Malaysia Perlis (UniMAP). The Investigation is focused on identifying and measuring the performance in terms of strength or weakness of the fixator that is needed before the application to the human body. Hence, this research was conducted to determine the performance of Uniaxial external fixator which was based on geometry using different screw drilling techniques applied during an angled uniaxial compression load. Fig 1 shows the model of Uniaxial external fixator that is introduced by HUKM and UniMAP.

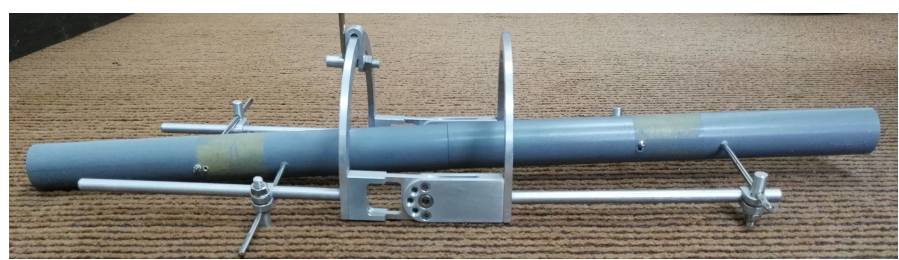

Fig. 1 Uniaxial external fixator.

\section{MATERIALS AND METHODS}

\section{Three-dimensional modelling}

A three-dimensional model of the femur diaphysis bone was created using SolidWorks 2014. This research was focused on the occurrence of oblique fractures to the femur diaphysis bone. The bone was hypothesised to partially heal from the fracture after 8-28 weeks, right after the installion of the fixator for an adult $[7,8]$. Hence, there was no fracture gap in the bone model. In order to simplify the simulation process, the compact bone was only included in the model [9]. A simple bone geometry was used so that the results would not be affected by this hypothetical assumption since the fracture analysis was performed using different loadings and material settings, without changes to the bone geometry [10].

The three-dimensional external fixator was installed to the bone model by referring to the standard medical procedures. Pin insertion dimension was dependent on the pin used. There were two types of pin insertion techniques, namely predrilling and selfdrilling [11]. Fig. 2 demonstrates the pins insertion techniques of predrilling and selfdrilling. For predrilling, conventional threaded screws with a smooth conical tip should be inserted bicortically and fully threaded in the predrilled hole of the far cortex butshould by not protruding too far as it might cause soft tissues injuries. Self -Drilling of Schanz screws with a sharp tip on the other hand should not perforate the far cortex as this would cause soft tissue damage if ther were projected beyond the cortex $[12,13]$. Therefore, for the purposes of this research, both pin insertion methods were applied to the external fixator-bone model. A $2.00 \mathrm{~mm}$ length from the end of the cortex to the pin tip for conventional threaded pin and a $2.00 \mathrm{~mm}$ length from the pin tip to the end cortex of the Schanz screw were used. Screw dimensions were neglected in the models for simplifying the simulation model as the results were not affected by these hyphothetical assumptions since the analysis was focused on the loading and material settings without changing the screw dimensions.
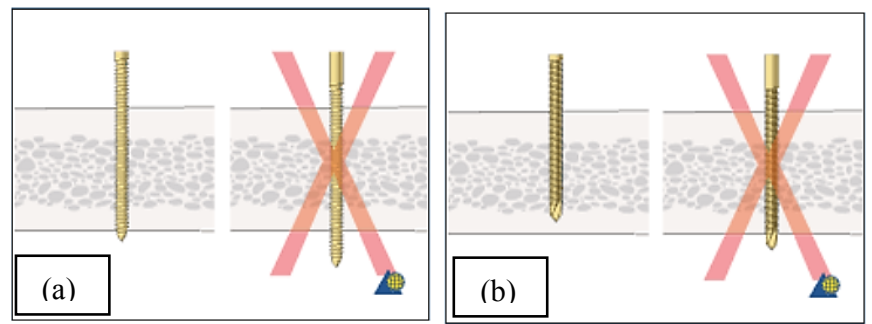

Fig. 2 Pin insertion for (a) predrilling and (b) self-drilling screws [11].

Finite element analysis

The external fixator-bone models were imported into ANSYSv14.5 Workbench to convert the completed three-dimensional model to the finite element model. A titanium alloy (Ti-6Al-4V) fixator and compact bone with elastic modulus of $110 \mathrm{GPa}$ and 13.7 GPa with same Poisson ratio of 0.3 were set as homogenous and linear isotropic materials because the mechanical properties in all the points were exactly the same as there was no change in the direction and the original shape was restored when force was removed $[1,2,9$, 14, 15]. The meshing of the fixator-bone models used 10-noded tetrahedral element since 4-noded tetrahedral elements provided poor stress predictions compared to the 10-noded tetrahedral element which produced much more accurate results [9]. Fig. 3 shows the meshing of both external fixator-bone models.

There were two different cases of loading in this research. In Case 1 , compression of $60 \mathrm{~N}$ with $90^{\circ}$ from X-axis by increment of $240 \mathrm{~N}$ until $6300 \mathrm{~N}$ were applied to the upper end of the femur diaphysis bone, representing the loading of patient's activities to the femur bone as seen in Table 1 . In case 2 , compression of $10 \mathrm{~N}$ with $90^{\circ}$ from $\mathrm{X}$ axis by increment of $5 \mathrm{~N}$ until $100 \mathrm{~N}$ were applied to the to the upper end of fixator for the purposes of reviewing the effect of environment loading to the femur bone. In addition, angled compressive force with constant force by decrement of $15^{\circ}$ were applied in both cases to obtain a more realistic analysis. The bottom end of the bone was fixed using the four pins attached to the fixator that fixed in X-and Z-axis while freeing the $\mathrm{Y}$-axis in order to avoid rigid body movements during the analysis [2]. Fig. 4 demonstrates the loading and boundary conditions of predrilling model for both cases.

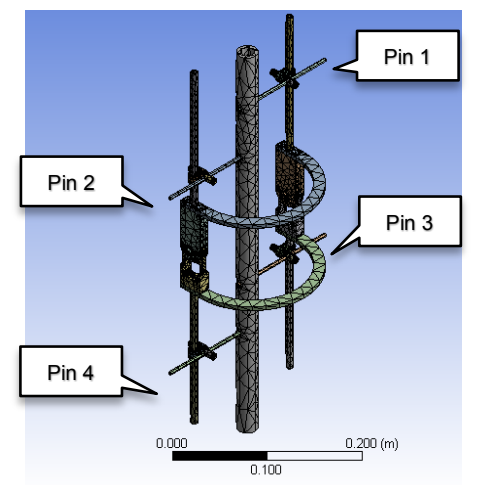

Fig. 3 Meshing of predrilling technique external fixator-bone model.

(a)

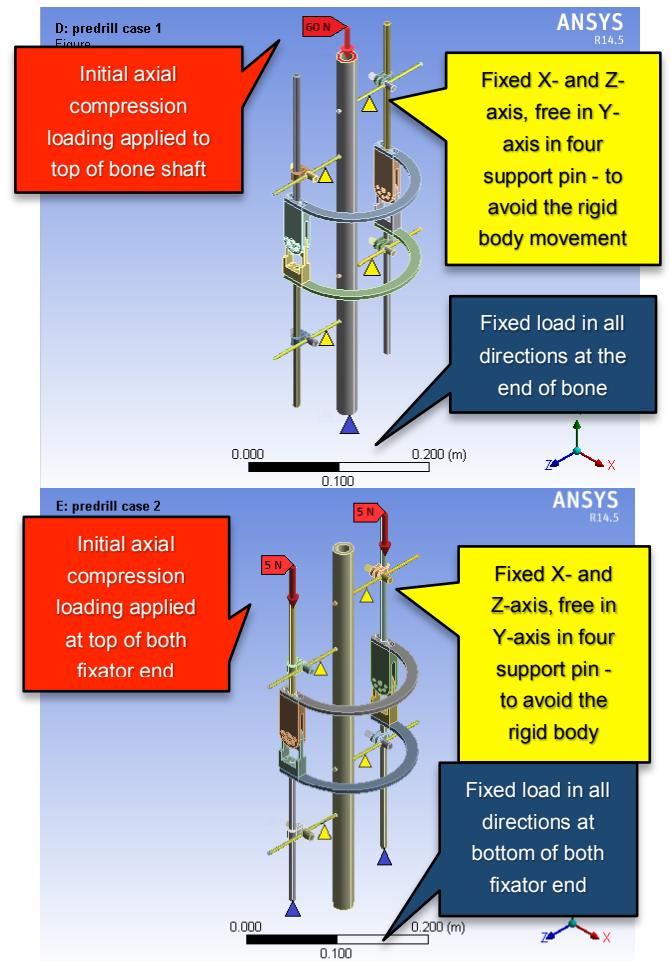

Fig. 4 Loading and boundary conditions of predrilling model for (a) Case 1 and (b) Case 2. 
Table 1 Daily activities of patient with $62.65 \mathrm{~kg}$ at femur distal bone [2, 16, 17].

\begin{tabular}{ccc}
\hline Activities & $\begin{array}{c}\text { Total Body } \\
\text { Weight } \\
\text { (BW) }\end{array}$ & Force (N) \\
\hline Swing (Walking) & 0.1 & 61.46 \\
Double leg standing (Walking) & 0.5 & 307.30 \\
Walking & $2.2-2.5$ & $1352.11-1536.49$ \\
Ascending stairs & 2.39 & 1468.89 \\
One leg standing & 2.47 & 1518.05 \\
Descending stairs & 2.72 & 1671.70 \\
Running & 9.98 & 6133.67 \\
\hline
\end{tabular}

\section{RESULTS AND DISCUSSION}

\section{Deformation}

In Case 1, it was found that magnitude of the deformation for both predrilling and self-drilling models were located at the upper pin-bone interaction based on the contour plots of Fig. 11(a) and 12(a). The peak value of deformation was $5.6120 \times 10^{-6} \mathrm{~m}$ and $5.8622 \times 10^{-6} \mathrm{~m}$ for predrilling and self-drilling models with a difference of $4.27 \%$ when swinging leg. With reference of Fig 5, it could be said that both models demonstrated similar trends as they deformed more from the original point when the value and angle of loading were increased. Hence, $90^{\circ}$ from $\mathrm{X}$-axis of the compression loading has a much greater value of deformation in comparison to other angles. Furthermore, both the predrilling model and self-drilling model demonstrated no differences in terms of deformation.

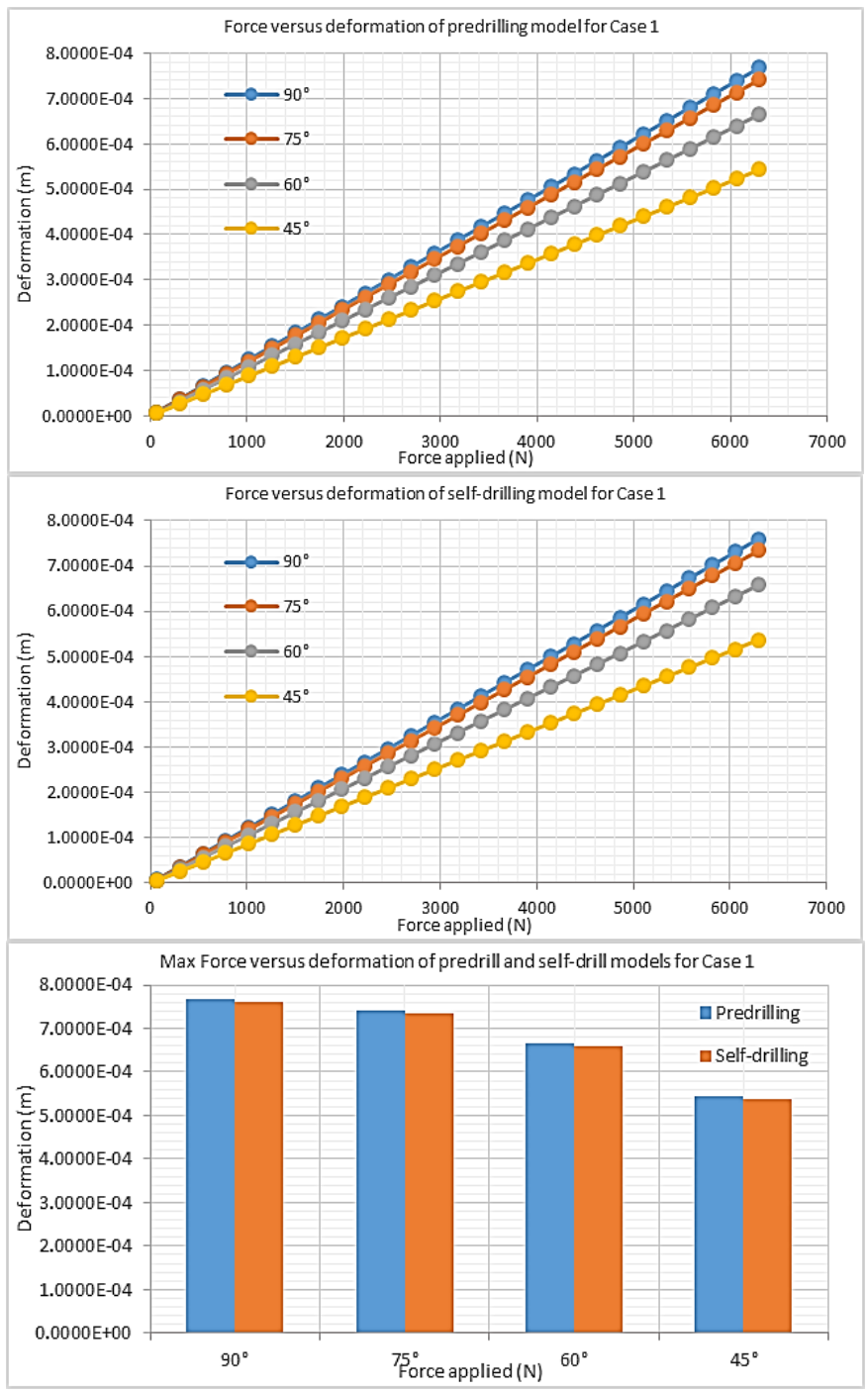

Fig. 5 Force versus deformation graph of predrilling and self-drilling models for Case 1.
In Case 2, neglation of the existence of fixator demostrated that the maximum magnitude of the deformation for predrilling and selfdrilling models were located at the highest pin-bone interaction. Deformation of the bone was lower when the pin-bone interaction position became lower. The peak value of deformation was $2.1316 \times 10^{-7} \mathrm{~m}$ and $2.1803 \times 10^{-7} \mathrm{~m}$ for predrilling and self-drilling with a difference of $2.23 \%$ when an object with $10 \mathrm{~N}$ fell onto the top of the fixator. From Fig 6, both models projected exactly the same trend. Increased force and degree entailed an increase in the value of deformation. In addition, the self-drilling and predrilling methods showed no obvious differences in deformation when compared.

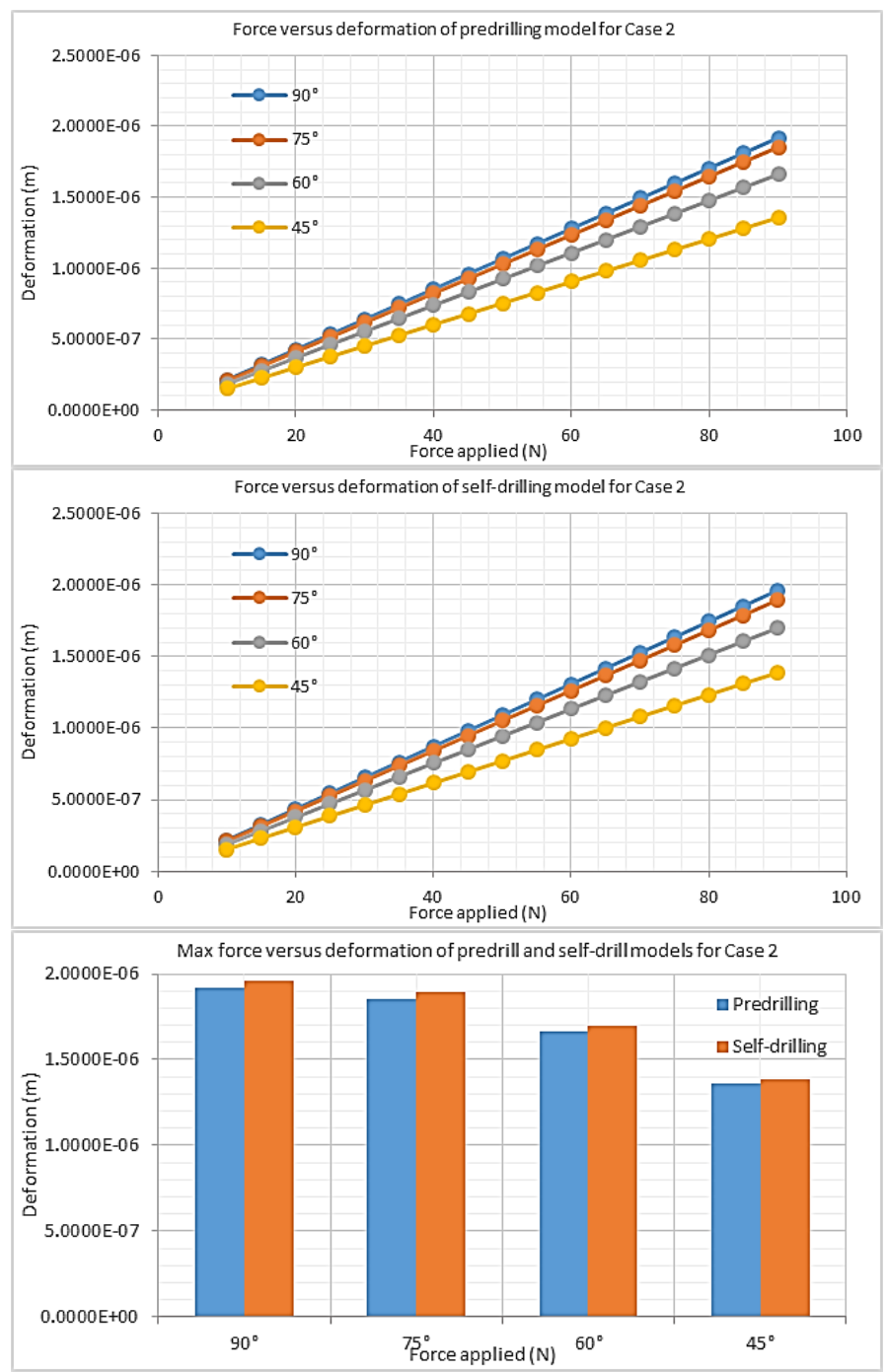

Fig. 6 Force versus deformation graph of predrilling and self-drilling models for Case 2.

In this research, it was found that there was is no obvious differences in the deformation for both Cases 1 and 2 when comparing both the screw drilling techniques due to the use of same geometry models with same dimensions for both analysis models [14]. Based on previous studies, Ramlee et al. observed that there was a significant difference within the three external fixator designs such as Delta, Mitkovic and Unilateral [2]. For long term clinical results, use of Unilateral fixator should be avoided as it was found that maximum displacement produced by Unilateral fixator was at least three times greater than Mitkovic and Delta when simulating the swing phase from finite element prediction. Hence, it could be said that the effects of the screw inserting techniques on the performance of fixator in this research were minor and couldbe ignored. Futhermore, $90^{\circ} \mathrm{of}$ compression loading from $\mathrm{X}$-axis has the greatest magnitude of deformation for both models in cases 1 and 2. This was because the force was reduced as opposed to the $\mathrm{Y}$-axis based on the Cartesian vectors theory that was applied to solve 3D problems. 


\section{Von Mises strain}

The highest von Mises strain revealed that at the lowest pin-bone interaction for both models from the contour plots of Fig 11(b) and 12(b). The maximum von Mises strain for predrilling was $4.1611 \times 10^{-5}$ $\mathrm{m} / \mathrm{m}$ while for self-drilling was $3.9572 \times 10^{-5} \mathrm{~m} / \mathrm{m}$ with a difference of $4.90 \%$ during the swing stage. It was shown that similar trends were exhibited between predrill and self-drill models when comparing the various degree and forces. Fig. 7 shows that the value of strain was increased when there was an increase in forces and degrees. In addition, the graph of force versus von Mises strain in $90^{\circ}$ for predrilling was slightly inclined when compared with self-drilling. Although both models have the same peak von Mises strain point and trend, but the strain distribution pattern wase different. It could be seen that the strain value higher when pin-bone interaction position became lower for predrilling. However, the strain values for upper and bottom pin-bone interaction of self-drilling were slightly greater than the middle pin-bone interaction, as observed from graph of force versus von Mises strain.
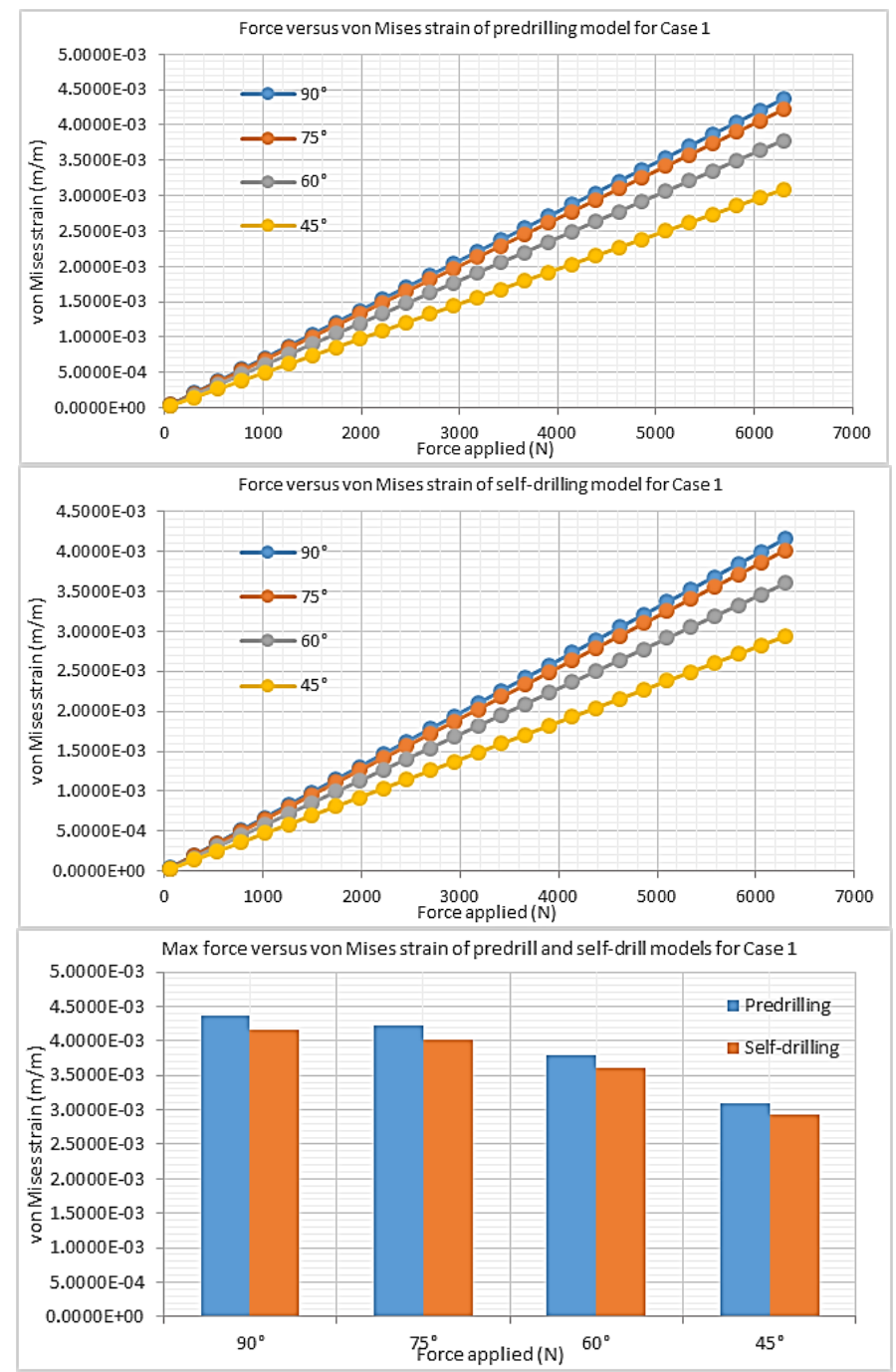

Fig. 7 Force versus von Mises strain graph of predrilling and selfdrilling models for Case 1.

For Case 2, the negation of fixator caused the highest von Mises strain to demonstrate lowest pin-bone interaction for both models. The maximum von Mises strain for predrilling was $1.1771 \times 10^{-6} \mathrm{~m} / \mathrm{m}$ while for self-drilling was $1.1085 \times 10^{-6} \mathrm{~m} / \mathrm{m}$ with a difference of $5.83 \%$ when $10 \mathrm{~N}$ object dropped at the top of the fixator. Besides, the strain value for upper and bottom pin-bone interaction of both models were slightly greater than the middle pin-bone interaction. There was a similar trend between the predrilling and self-drilling models in terms of various degree and forces when compared. Fig 8 shows that the value of strain was increased due to the increasing of forces and degrees. In addition, the graph of force versus von Mises strain in $90^{\circ}$ for predrilling was slightly inclined than self-drilling.
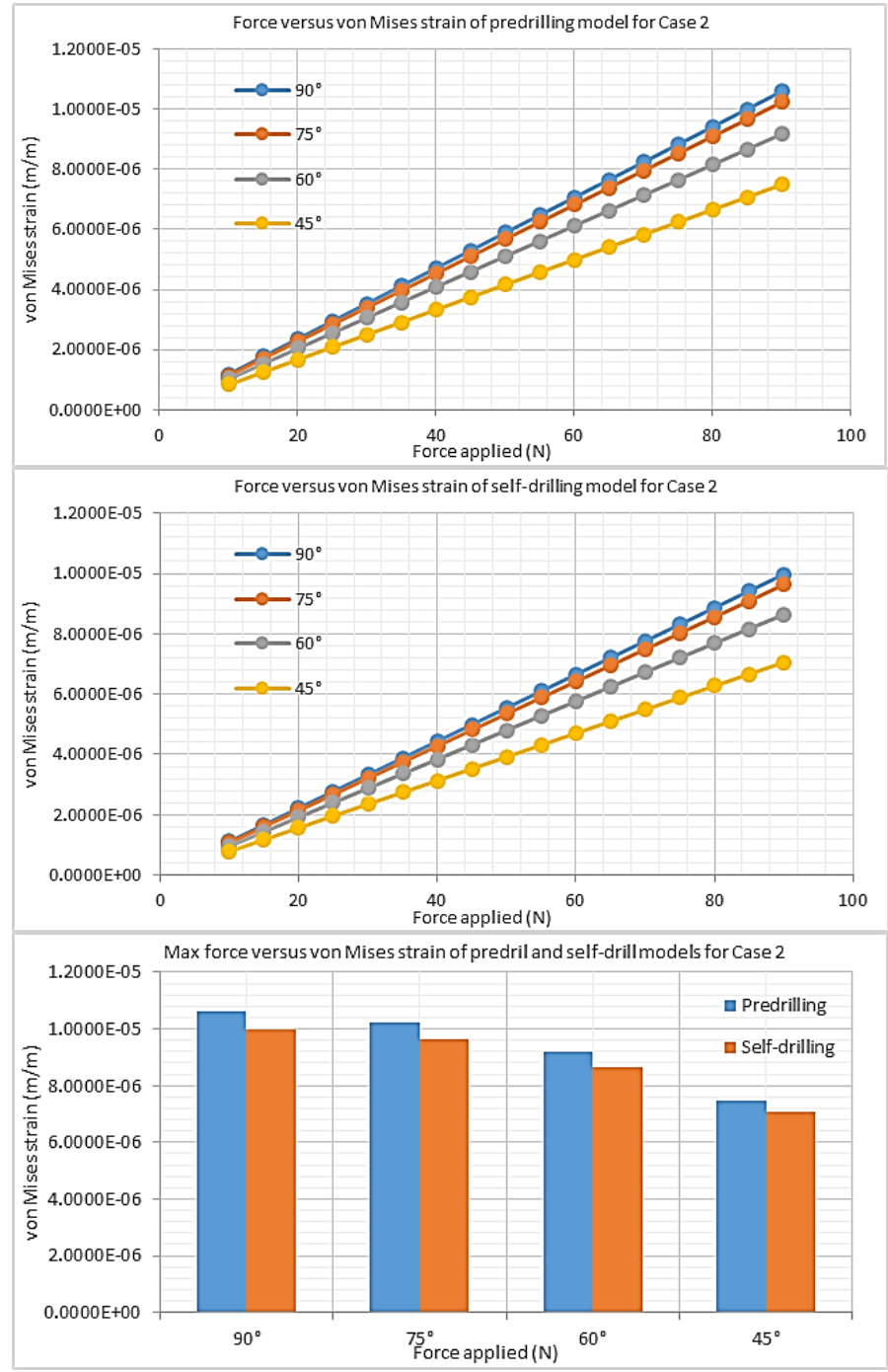

Fig. 8 Force versus von Mises strain graph of predrilling and selfdrilling models for Case 2.

It was observed that maximum von Mises strain in the bone appeared around the lowest pin-bone interaction position in both cases due to the fixed contact interface between screw thread and surrounding bone [18]. The maximum strain location followed the expected patterns that were demonstrated in previous studies [9]. Radovan et al. stated that high strains in either bone or implants might cause mechanical failure while stress shielding might occur during low strains in bone which led to the bone atrophy, bone resorption and implant losening [19]. However, Bujtár et al. observed that lower strain value of implant indicated the longer-term integrity [20]. Therefore, it could be said that self-drilling model was likely superior than the predrilling model in term of lower strain.

\section{Von Mises stress}

From Fig 11(c) and 12(c), the peaks for von Mises stress were observed at the lowest pin-bone interaction for both models which were in line with previous studies by way of negation of the fixator. The highest stress for predrilling was $0.5560 \mathrm{MPa}$ while self-drilling was $0.5364 \mathrm{MPa}$ with different of $3.53 \%$ during swing phase. Moreover, both models have almost similar trends. Fig 9 indicates that stress was increased when the values of force and degree were added. Furthermore, force against von Mises stress graph for predrilling was a bit more slanted than self-drilling. 


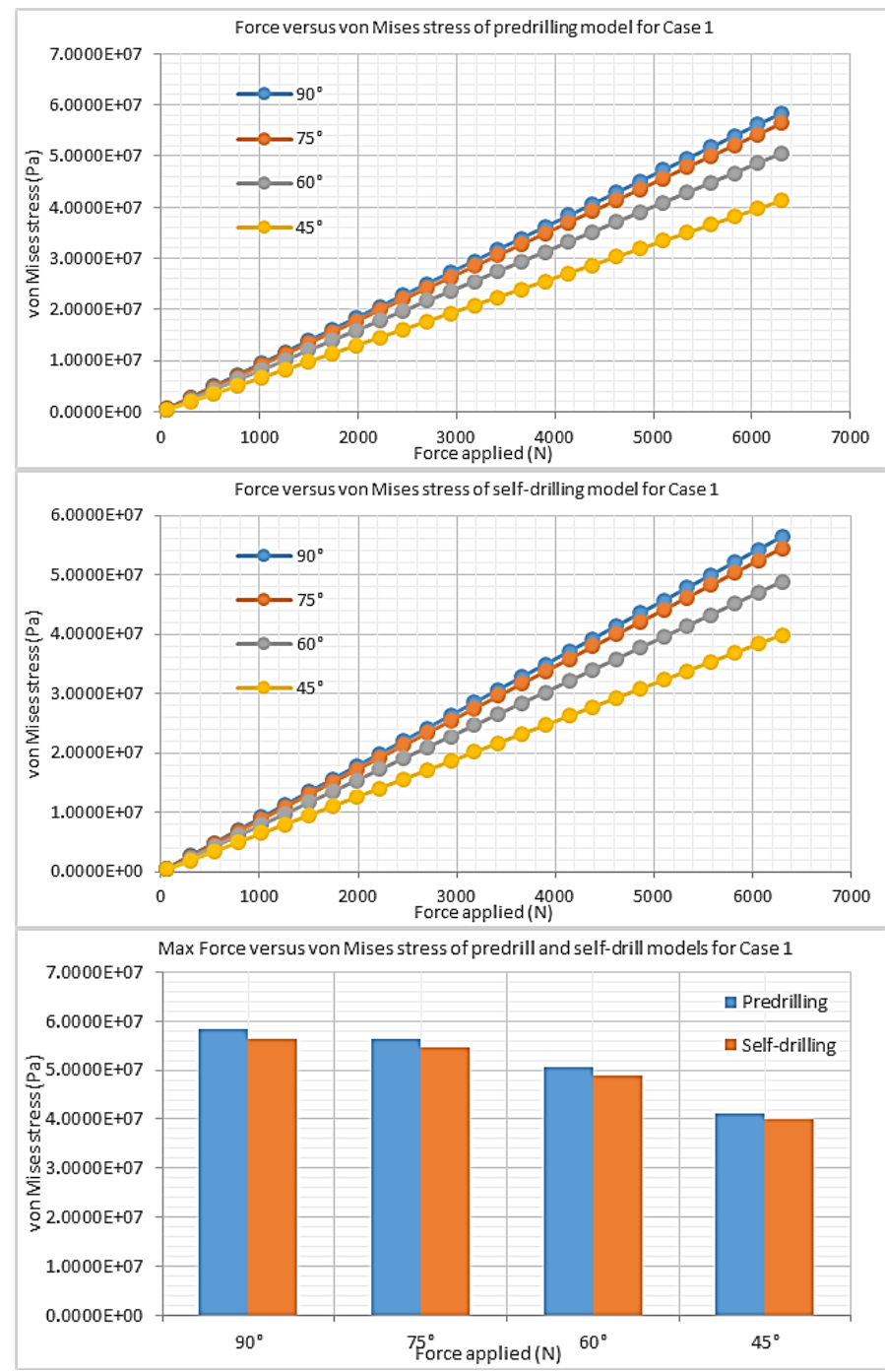

Fig. 9 Force versus von Mises stress graph of predrilling and selfdrilling models for Case 1.

The peak von Mises stress was observed at the lowest pin-bone interaction for both models with the negation of the fixator. The highest stress for predrilling was $15.89 \mathrm{kPa}$ while self-drilling was $14.80 \mathrm{kPa}$ with a difference of $6.82 \%$ when top of fixator received the force of a $10 \mathrm{~N}$ object. In addition, it projected similar pattern with von Mises strain as the stress value for upper and bottom pin-bone interaction of self-drilling were slightly greater the middle pin-bone interaction for self-drilling. Moreover, both models have almost similar trends. Fig 10 indicates that stress was increased when the values of force and degree were increased. Furthermore, force against von Mises stress graph for predrilling was a bit more slanted than selfdrilling.

The high von Mises stress of bone was found to appear at the lowest pin-bone interface in both cases which were in line with previous studies [2]. Stress concentrations that appeared in this region would cause an unstable fixator construction that might result in pain and screw loosening. Therefore, it could be said that lower stress magnitudes of self-drilling model has better performance than predrilling model in this research. Previous studies showed that stress onto fixators which was fixed at unstable sites recorded in $266.7 \mathrm{MPa}$ for Delta, 286.0 MPa for Mitkovic and 509.2 MPa for Unilateral, suggesting that these models provided adequate stability with minimal risk of implants failure. Similarly in this research, although in both cases it was demonstrated that the maximum von Mises stress magnitudes at the fixator pins with $1.8138 \mathrm{MPa}$ and $0.6338 \mathrm{MPa}$ for case 1 and 2 which 113 times greater than the stress at pin-bone interaction, but these stresses did not over ultimate strength of the material used which was 800-900 MPa for titanium alloys. Hence, in this research, the results obtained and discussed were more focused and detailed in emphasis on the bone rather than the fixator.
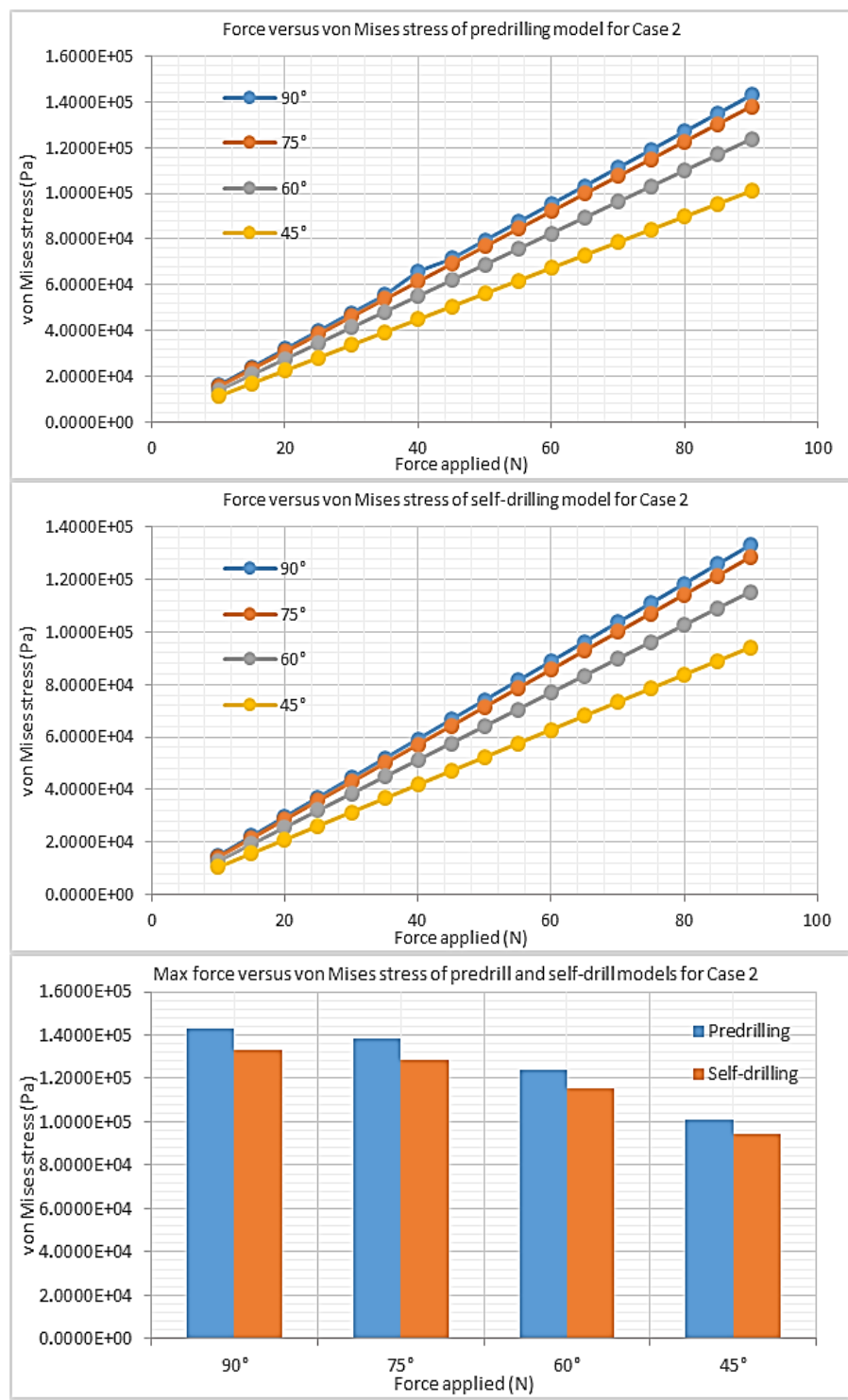

Fig. 10 Force versus von Mises stress graph of predrilling and selfdrilling models for Case 2.

In this research, there were some limitations that were needed to be considered. Firstly, the femur bone model that used in the FEA was simplified in geometry and properties. The bone was made using a hollow shaft with diameter of distal femur bone but in reality the femur bone has a different diameter along the bone. Although the results would not be affected by this assumption since fracture analysis was performed among different loadings and material settings without changes of the bone geometry. However, a more complex modelling would result in more realistic outcomes. The material properties for either fixator or cortical bone in this research were homogenous and linear isotropic. These materials were assumed to be more elastic and not easily overcomed by the yielding strength. However, both elastic and plastic properties should be considered in the analysis for obtaining a more realistic simulation. Therefore, further research should include the actual geometry model of femur bone and not only consider elastic but also plastic properties. Additionally, this research was only focused on the effects to the bone in order to review the critical stress location. Eventhough both models demonstrated peak von Mises stress at the fixator pin in the stress distribution, they did not exceed the ultimate strength of the material. Lastly, specialists in the orthopaedic fields should be involved in the research for providing added information about the standard surgical procedures. 


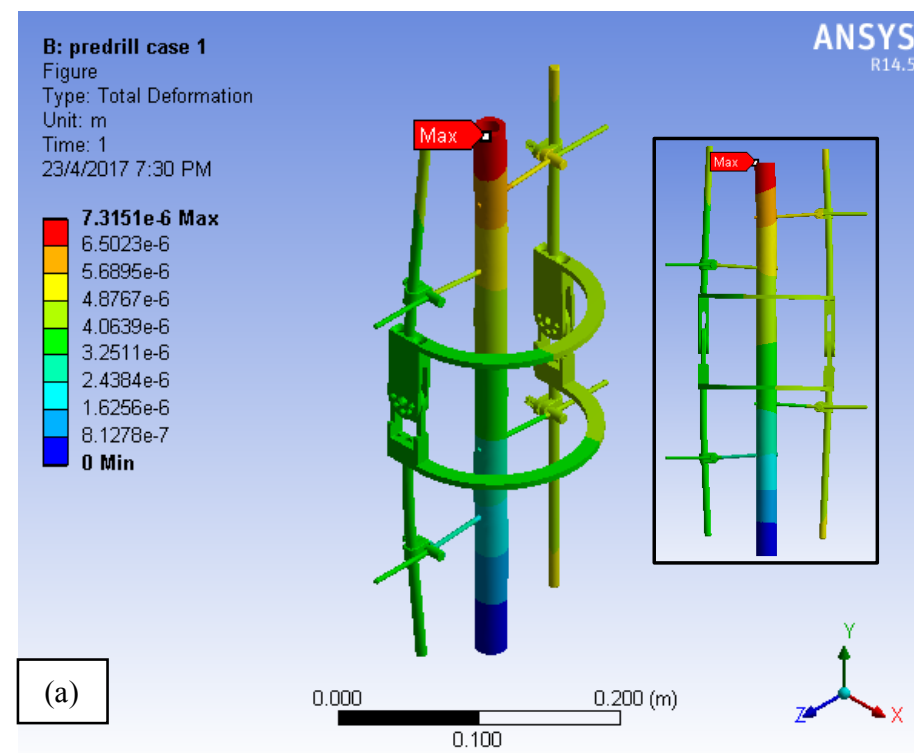

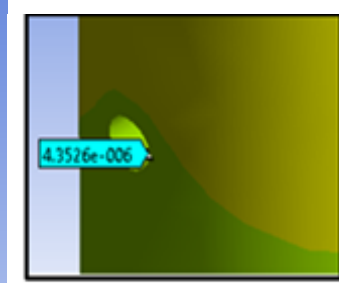

Pin 2

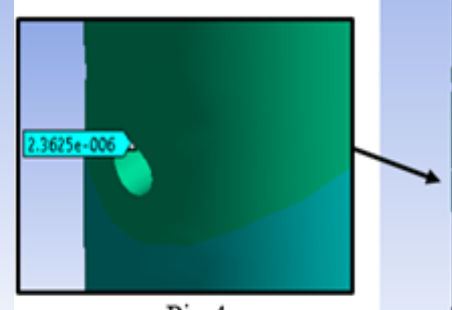

Pin 4

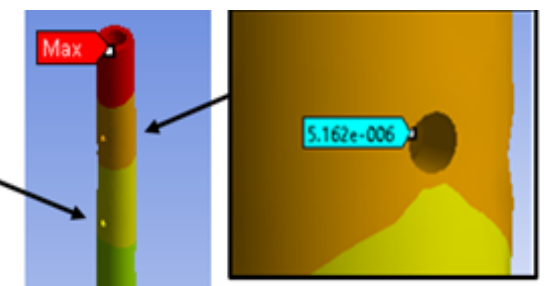

Pin 1

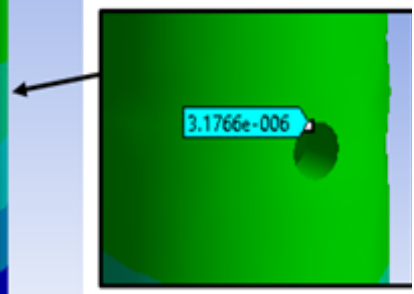

Pin 3

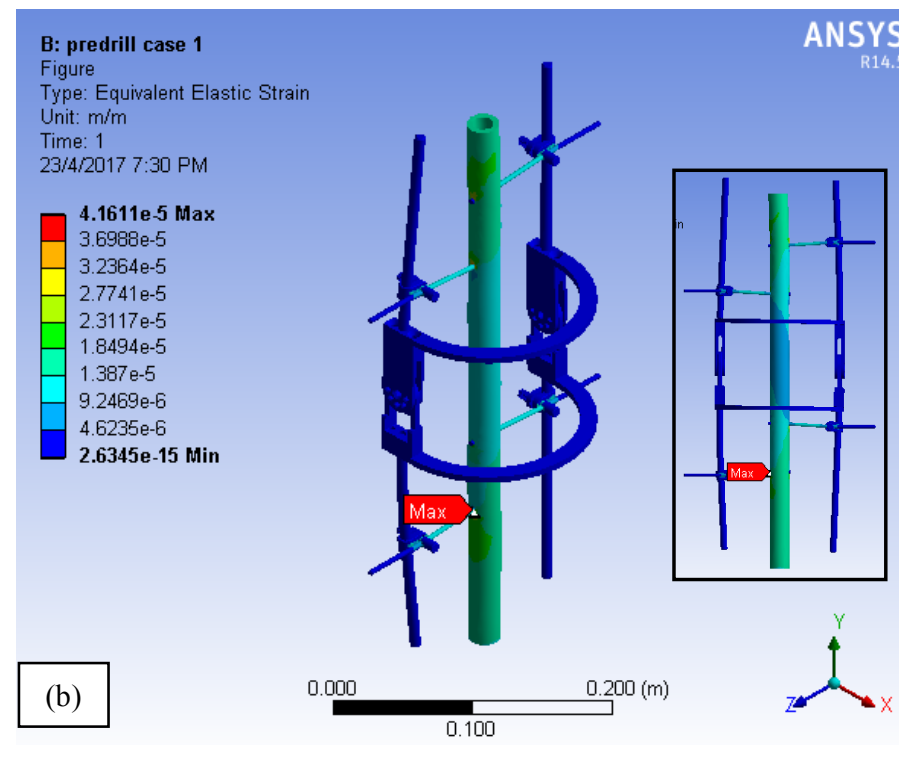

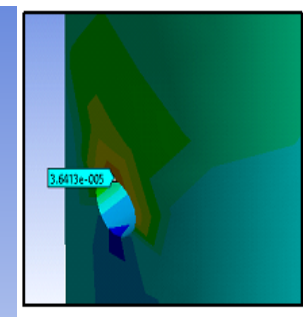

Pin 2

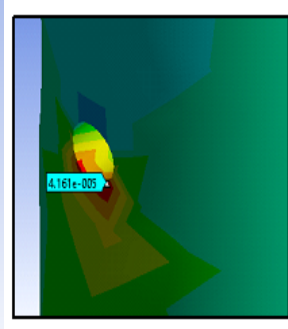

Pin 4

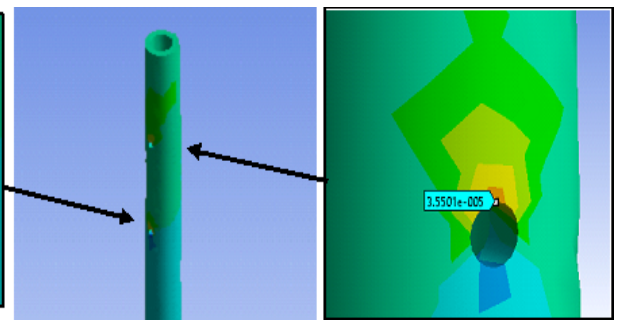

Pin 1

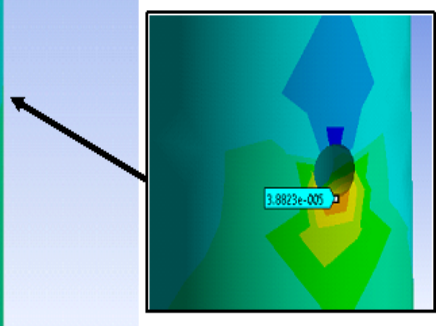

Pin 3
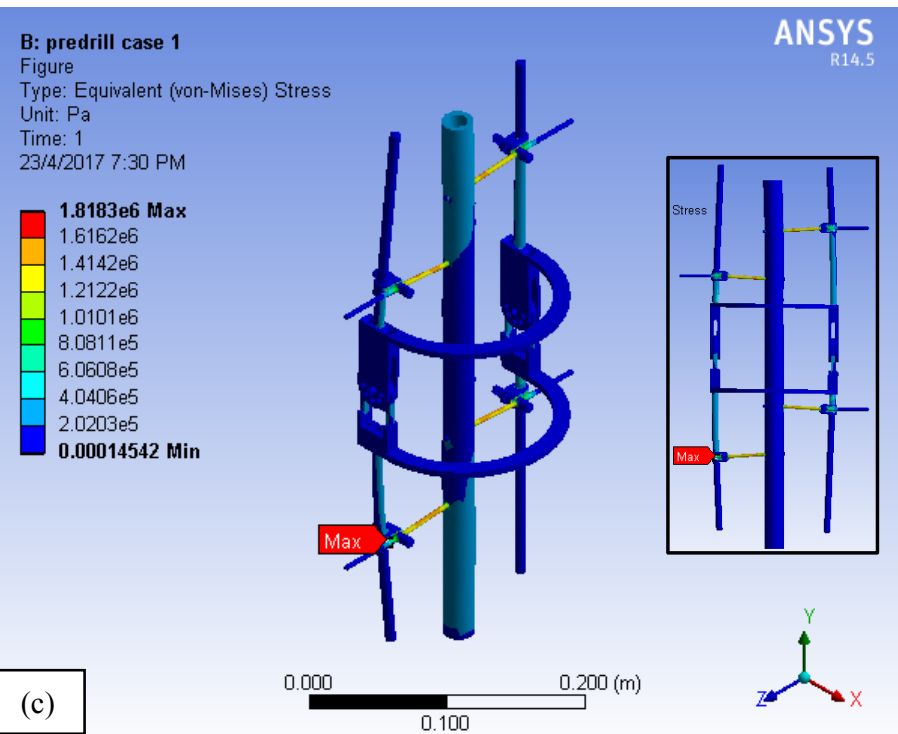

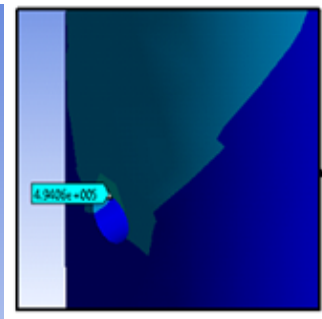

Pin 2

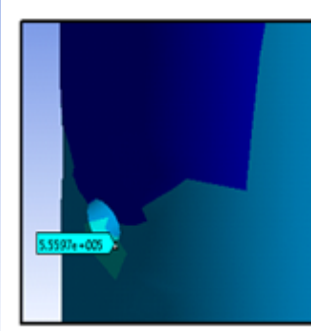

Pin 4
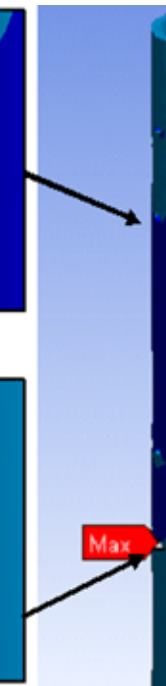

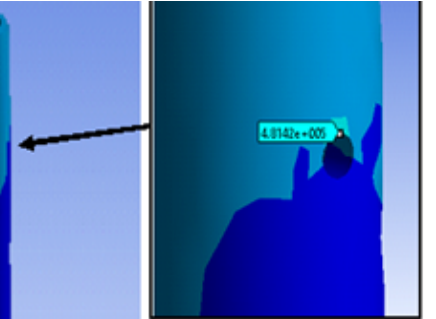

Pin 1

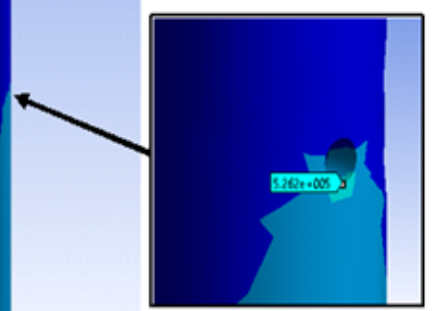

Pin 3

Fig. 11 Finite element analysis of external fixator-bone predrilling model for Case 1 of (a) deformation, (b) von Mises strain and (c) von Mises stress. 


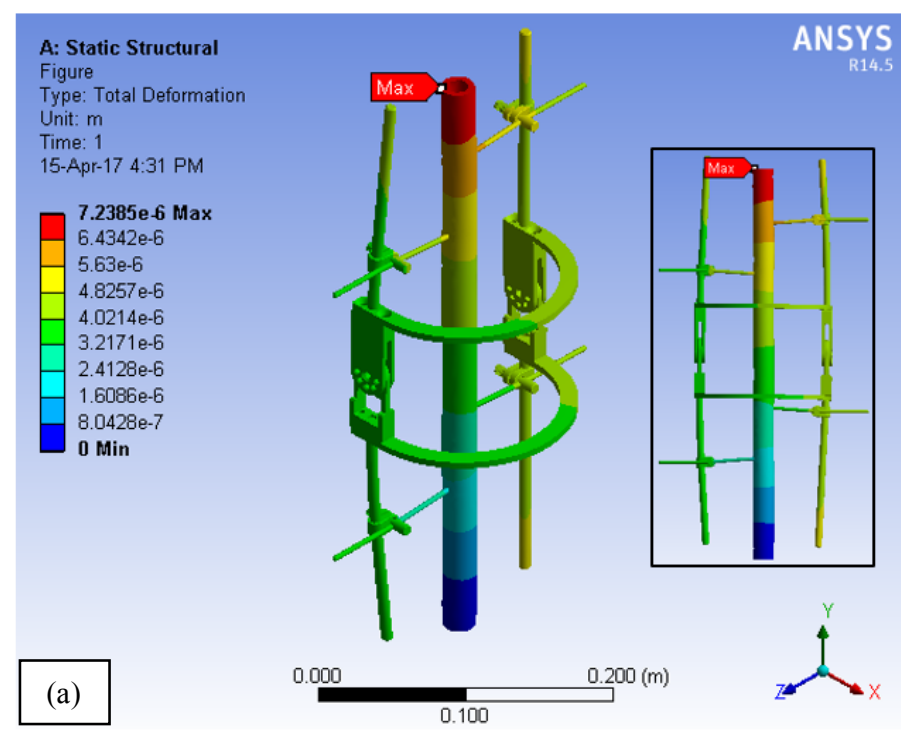

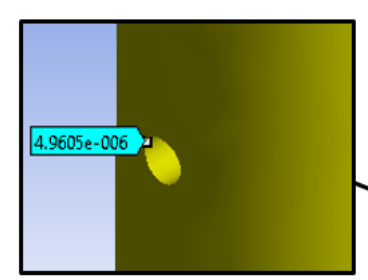

Pin 2

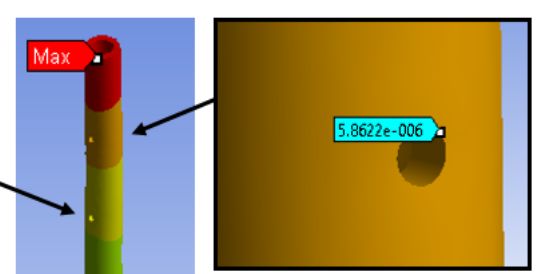

Pin 1

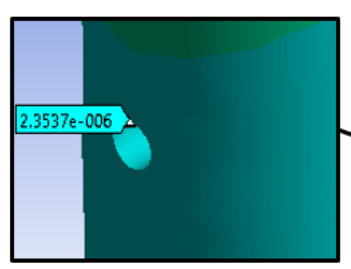

Pin 4

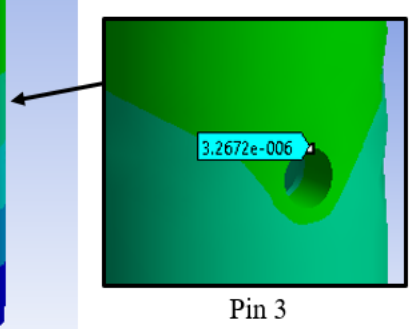

Pin 3

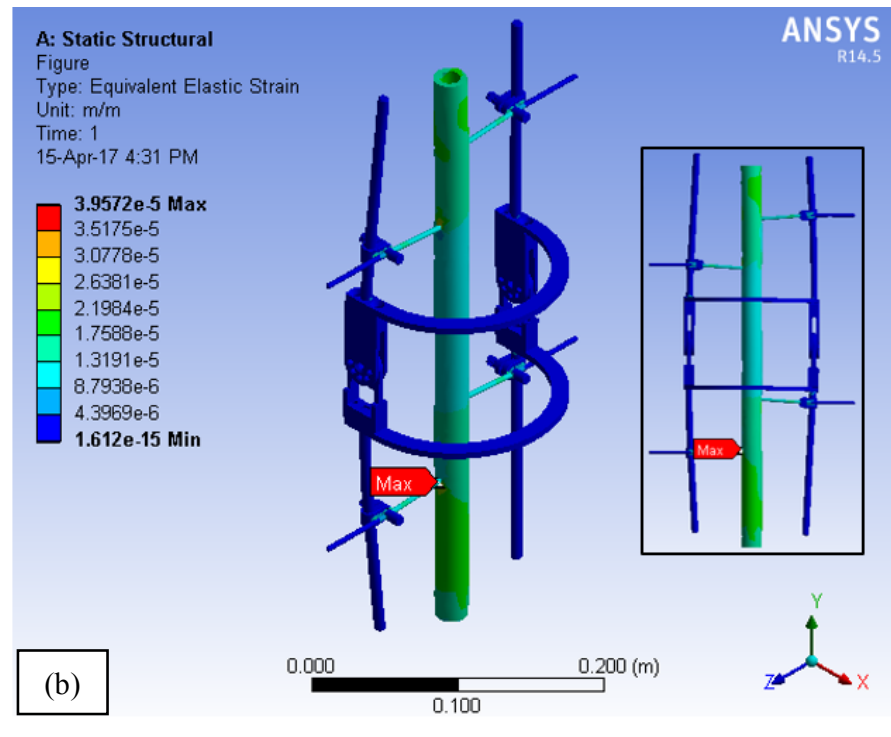

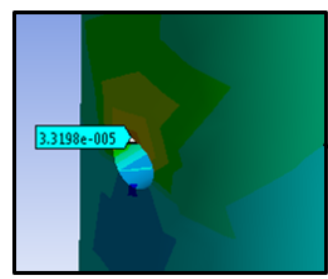

Pin 2

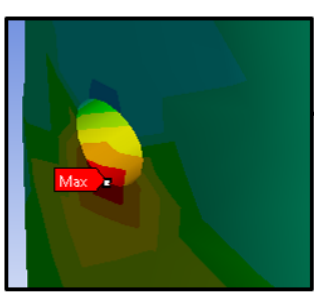

Pin 4
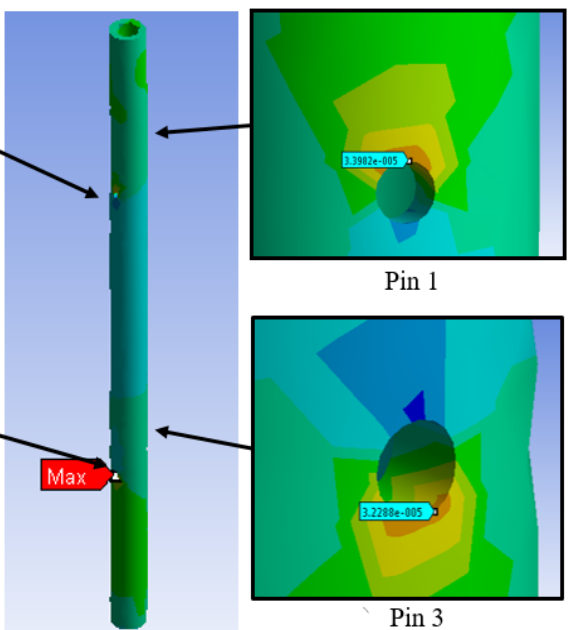

Pin 3
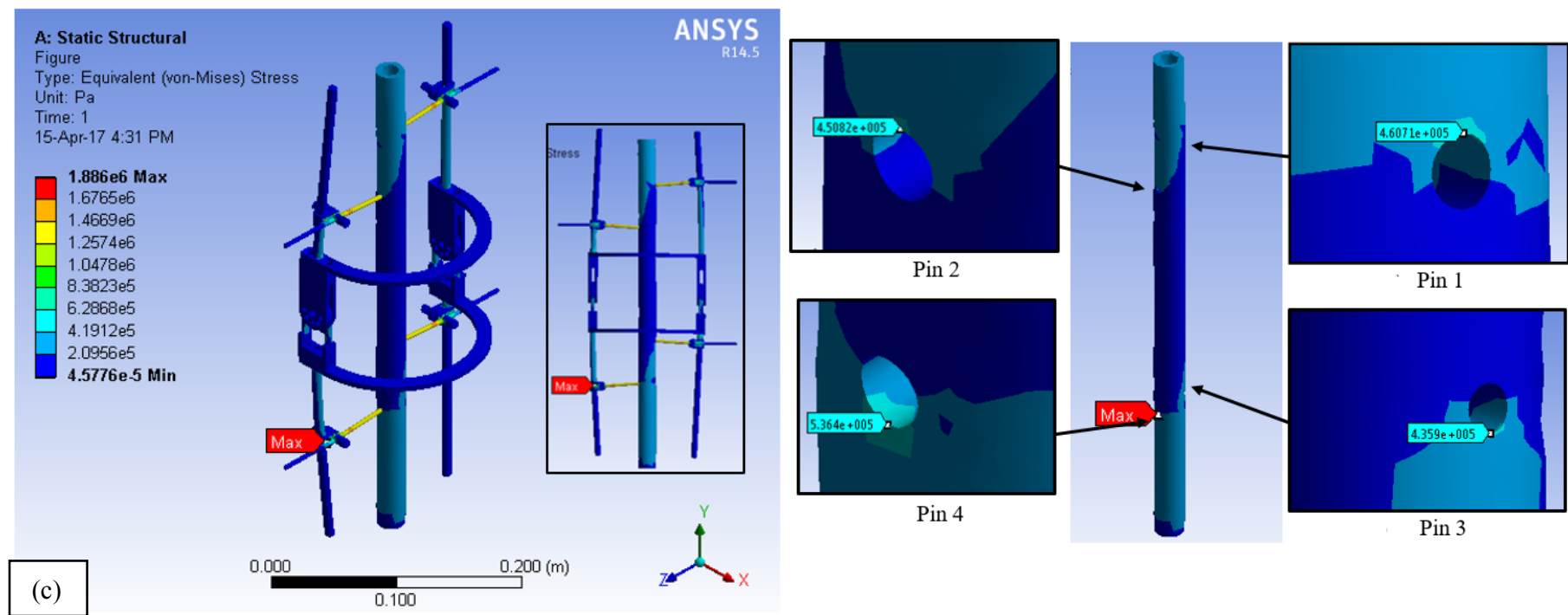

Pin 1
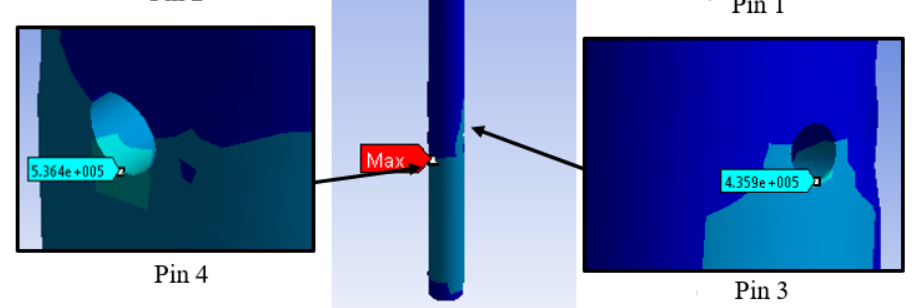

Pin 3

Fig. 12 Finite element analysis of external fixator-bone self-drilling model for Case 1 of (a) deformation, (b) von Mises strain and (c) von Mises stress. 


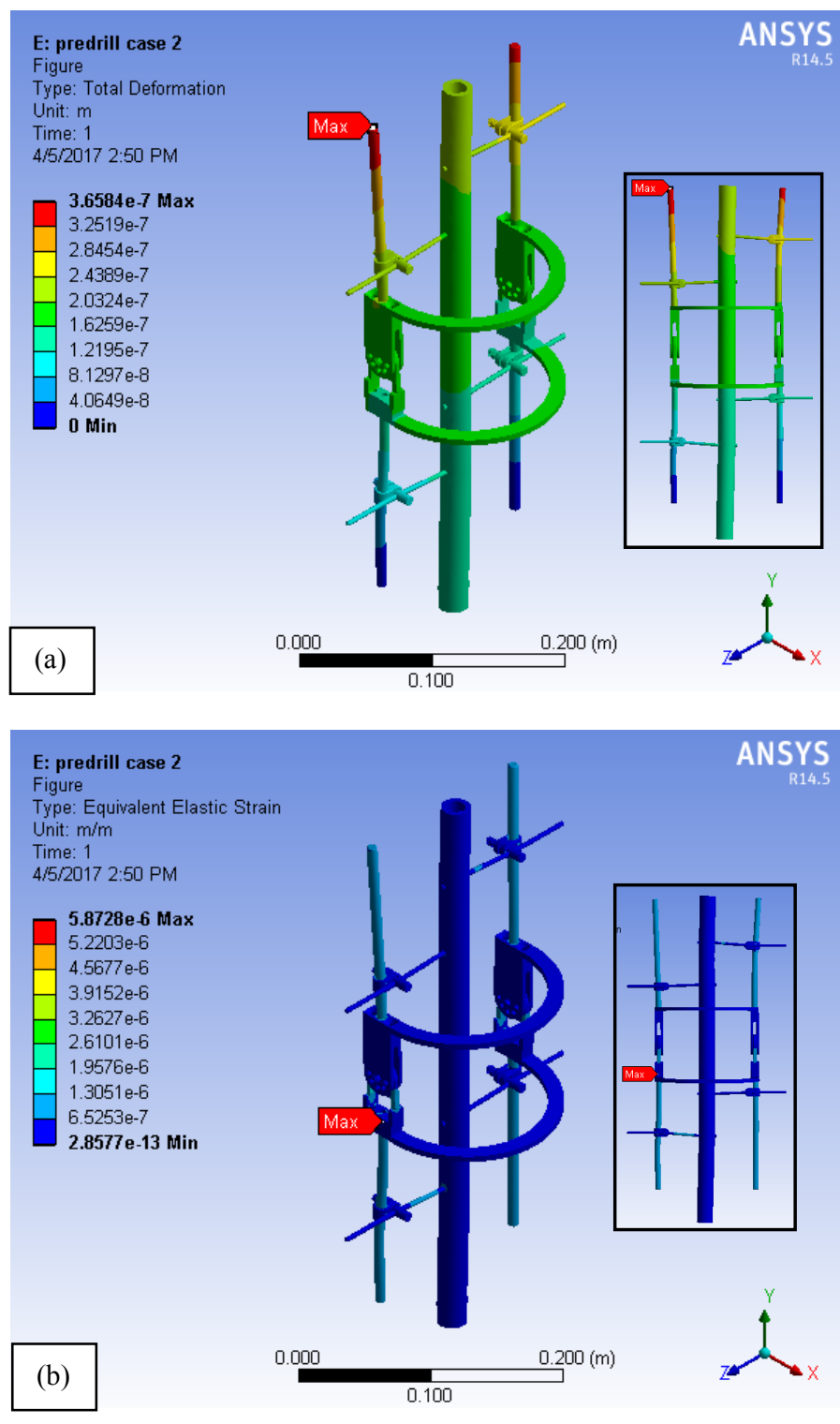

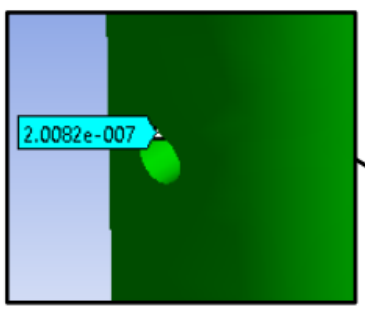

Pin 2

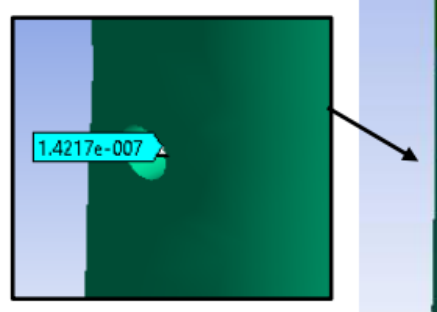

Pin 4

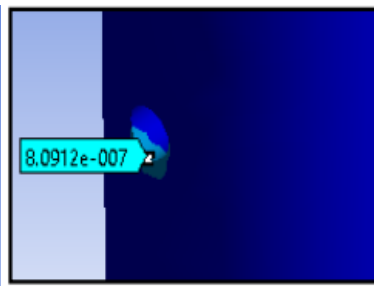

Pin 2

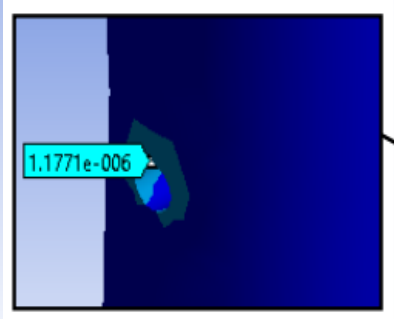

Pin 4

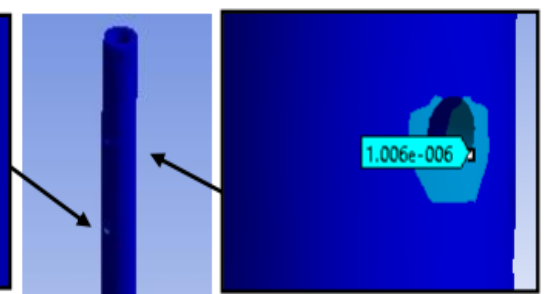

Pin 1

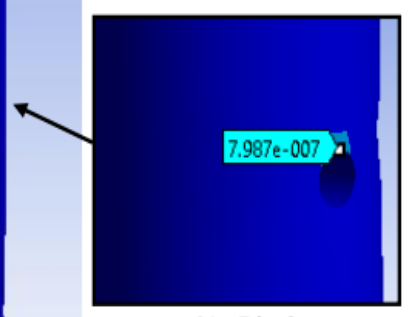

Pin 3

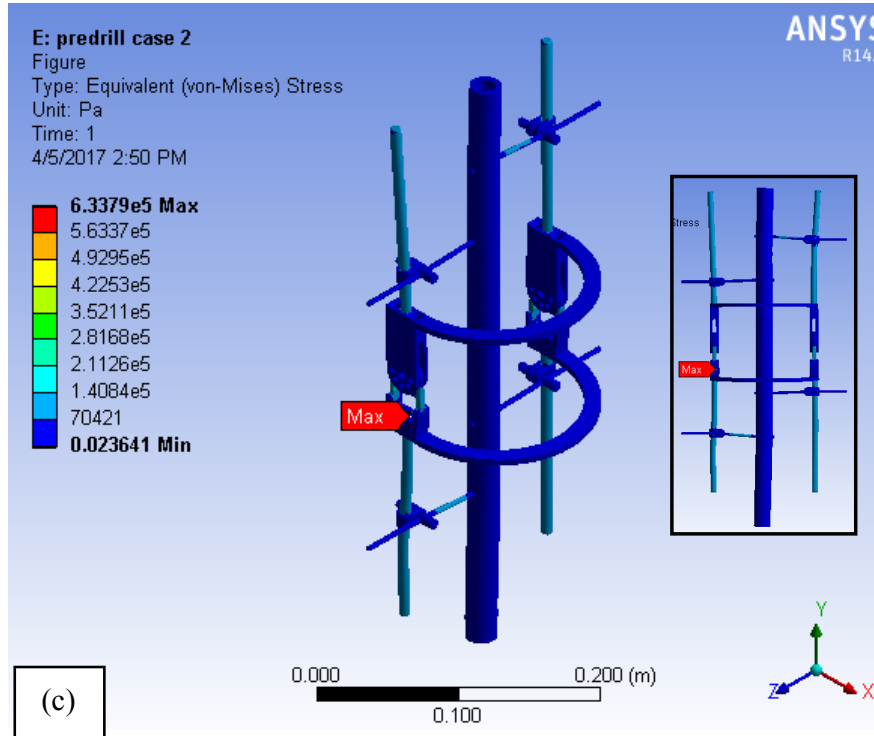

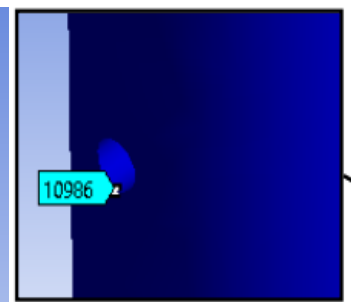

Pin 2

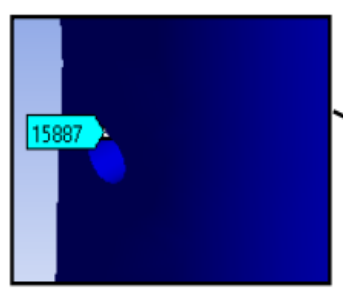

Pin 4

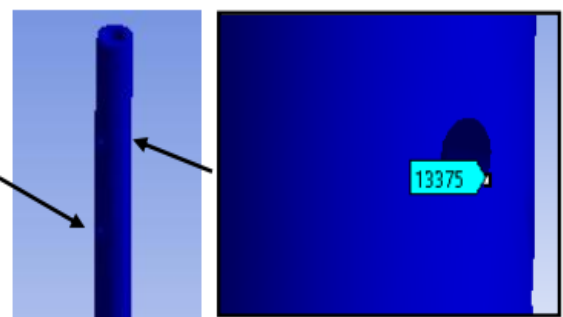

Pin 1

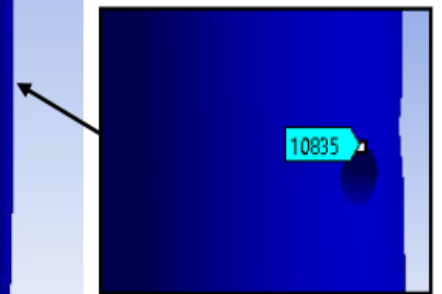

Pin 3

Fig. 13 Finite element analysis of external fixator-bone pre-drilling model for Case 2 of (a) deformation, (b) von Mises strain and (c) von Mises stress. 

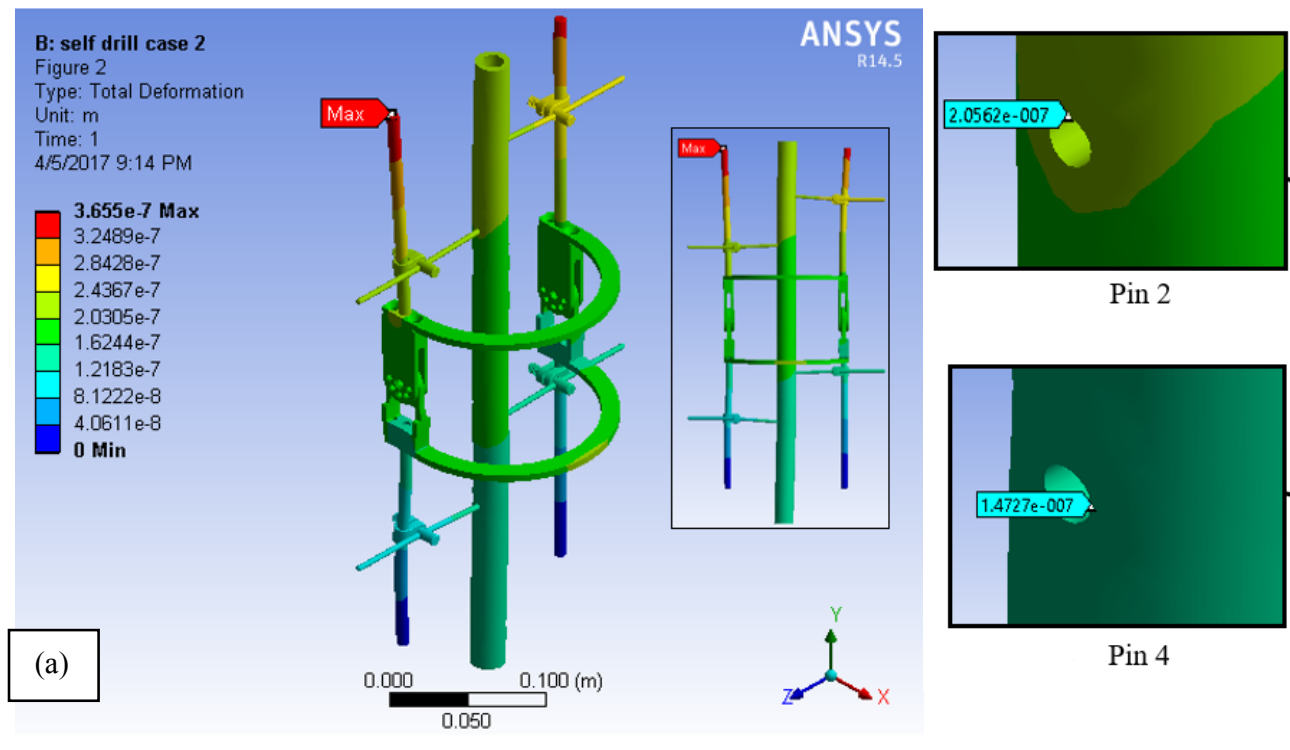

Pin 2

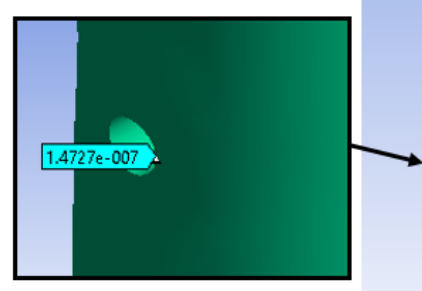

Pin 4
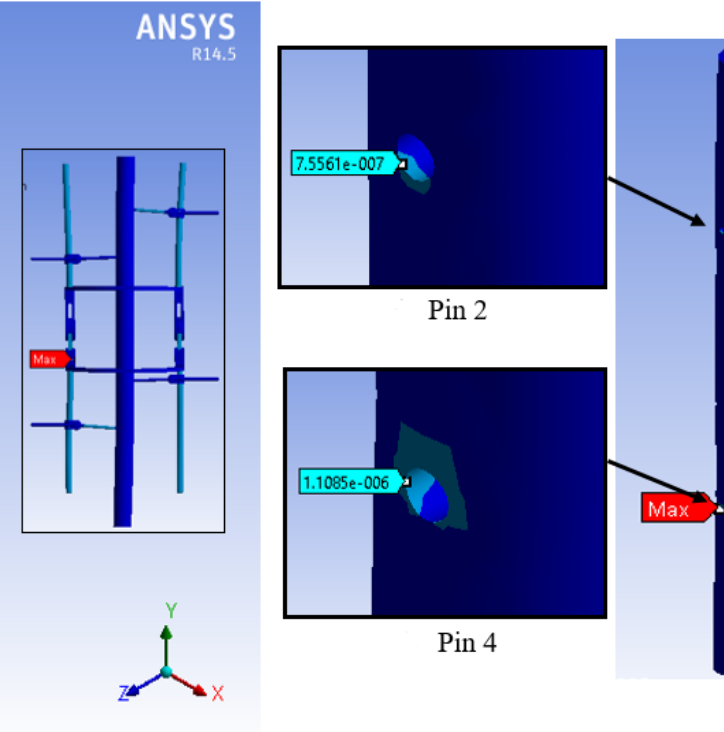

Pin 2

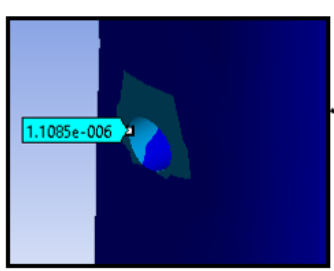

Pin 4
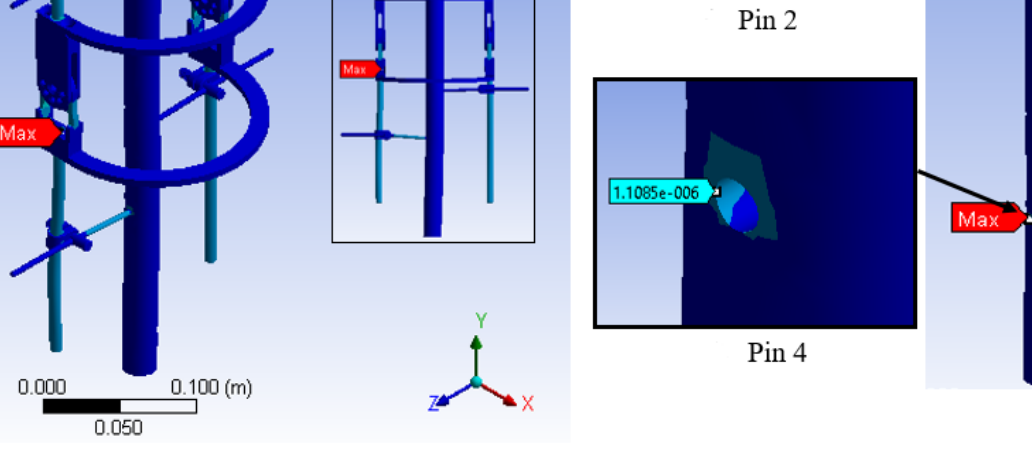

(b)
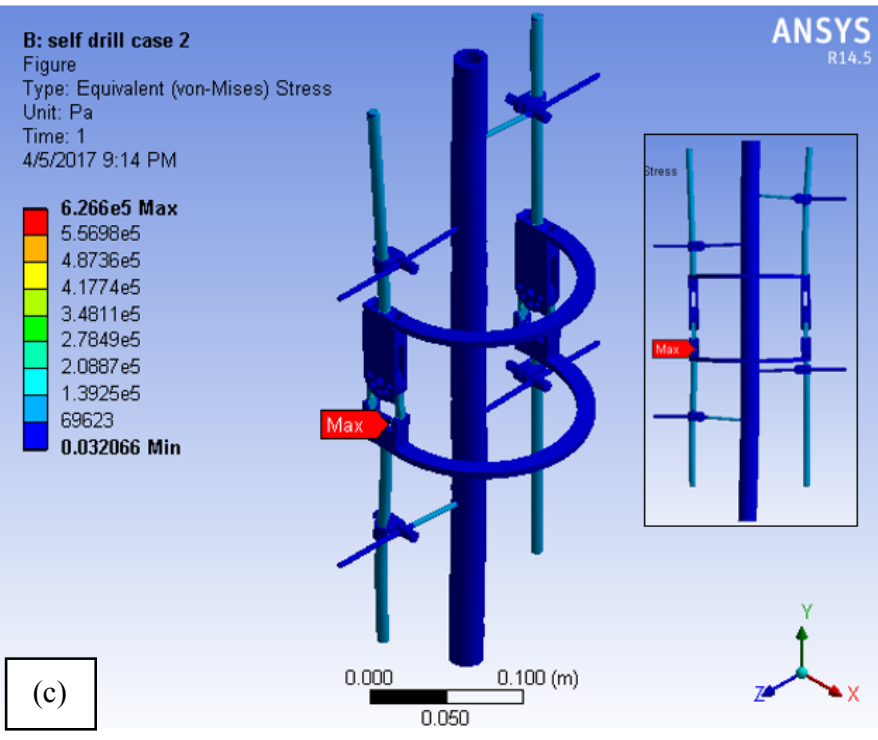

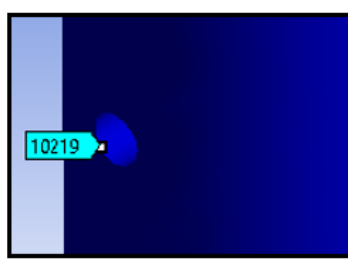

Pin 2

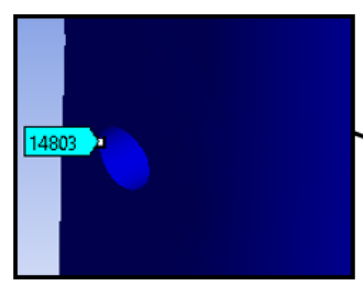

Pin 4

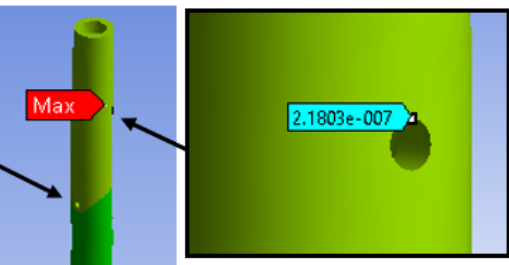

Pin 1

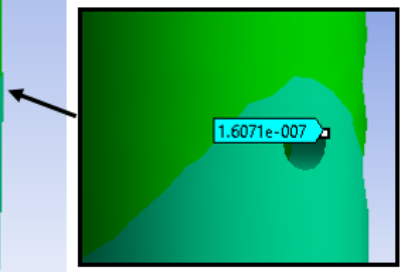

Pin 3

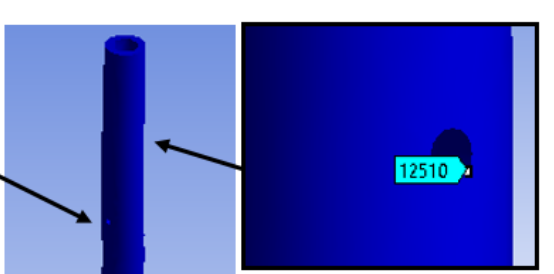

Pin 1

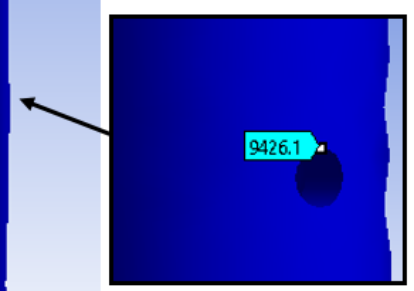

Pin 3

Fig. 14 Finite element analysis of external fixator-bone self-drilling model for Case 2 of (a) deformation, (b) von Mises strain and (c) von Mises stress. 


\section{CONCLUSION}

The new design of Uniaxial external fixator was introduced as a universal fixator in the application to all types of bone fracture as there were several types of fixators used in the orthopaedic treatment based on the types of fractures. Hence, studies for observing the performance of this design wereis conducted based on geometry via screw inserting techniques. The results from FEA suggested that selfdrilling screw technique's Uniaxial external fixator was-better than predrilling as it provided better stability and generated lower construct stresses.

There were contributions of this research to the society. Firstly, it provided additional information to the field of orthopaedic surgical since this research was focused on improving post-surgical teatments. Secondly, it also contributed in terms of improving the design of the fixator by reducing the shortcomings imposed on the bone and providing a better healing process to the bone. Next, it suggested the better screw insertion techniques to enhance the bone healing process.

\section{ACKNOWLEDGEMENT}

The author would like to acknowledge the support from the Ministry of Higher Education Malaysia via the Fundamental Research Grant Scheme (FRGS) under the grant number FRGS/1/2016/TK03/UNIMAP/03/4)

\section{REFERENCES}

[1] H. Mehboob, S. H. Chang, "Application of composites to orthopedic prostheses for effective bone healing: A review," Compos. Struct., vol. 118, pp. 328-341, 2014.

[2] M. H. Ramlee, M. R. Abdul Kadir, M. R. Murali, T. Kamarul, "Finite element analysis of three commonly used external fixation devices for treating Type III pilon fractures," Med. Eng. Phys., vol. 36, no. 10, pp. 1322-1330, 2014.

[3] M. S. Taljanovic, M. D. Jones, J. T. Ruth, J. B. Benjamin, J. E. Sheppard, B. Tim, "Fracture Fixation," Radio Graph., vol. 23, no. 6, pp. $1-13,2003$.

[4] "Nonunions," American Academy of Orthopaedic Surgeons, 2014.

[5] J. F. Barwick, P. J. Nowotarski, "Femur Shaft Fractures (Broken Thighbone)," American Academy of Orthopaedic Surgeons, 2011.

[6] C. Ma, C. Wu, J. Jiang, Y. Tu, T. Lin, "Metaphyseal locking plate as an external fi xator for open tibial fracture: Clinical outcomes and biomechanical assessment," Int. J. Care Inj., no. 8, 2016.

[7] C. Yang, H. Wang, Q. Zhu, J. Zhu, "External fixator followed by a plate for distraction, reduction, and fixation in neglected femoral diaphyseal fractures," Int. J. Care Inj., vol. 44, pp. 1087-1091, 2013.

[8] C. Gwinner, S. Märdian, T. Dröge, M. Schulze, M. J. Raschke, R. Stange, "Bicortical screw fixation provides superior biomechanical stability but devastating failure modes in periprosthetic femur fracture care using locking plates," Int. Orthop., vol. 39, no. 9, pp. 1749-1755, 2015.
[9] F. E. Donaldson, P. Pankaj, A. H. R. W. Simpson, "Bone properties affect loosening of half-pin external fixators at the pin-bone interface," Injury, vol. 43, no. 10, pp. 1764-1770, 2012.

[10] P. Ausiello, P. Franciosa, M. Martorelli, D. C. Watts, "Effects of thread features in osseo-integrated titanium implants using a statistics-based finite element method," Dent. Mater., vol. 28, no. 8, pp. 919-927, 2012.

[11] D. Höntzsch, P. V Giannoudis, H. C. Pape, M. Schütz, "Basic technique : Modular external fixation," AO Foundation, 2016. [Online]. Available:

https://www2.aofoundation.org/wps/portal/!ut/p/a1/jU_JDoIwFPyaXuk D4xJvPShxSYjBBXsxJZZCgm3zWiT69SJnXOY2k5nJDOU0o1yLe6 WEr4wW9ZvzySVKAOJVCpsk2YfA0kUYH5cAsBt3hvMXA5v14cPYPArv6Zc1Sbvp56ZzkczRTnKQqLEoMFOLr23bk6AQNu2USB MYRp97Q8GBlUnW0fAGvSiJuAaVBIfQ22lcZ5mgyXU3.

[12] H. Dankward, B. Suthorn, "AO Surgery Reference," AO Surgery Reference, 2016. [Online]. Available: https://www2.aofoundation.org.

[13] C. Colton and J. Orson, "Screws - Form and function," AO Trauma, 2012. [Online]. Available:

https://aotrauma.aofoundation.org/Structure/education/educationalprograms/operating-room-personnel/Documents/Screws_Handout.pdf.

[14] G. P. de Jesus, L. G. Vaz, M. F. R. Gabrielli, L. A. Passeri, T. V. Oliveira, P. Y. Noritomi, P. Jürgens, "Finite element evaluation of three methods of stable fixation of condyle base fractures," Int. J. Oral Maxilloficial Surg., vol. 43, pp. 1251-1256, 2014.

[15] O. Eraslan, Ö. Inan, "The effect of thread design on stress distribution in a solid screw implant: A 3D finite element analysis," Clin. Oral Investig., vol. 14, no. 4, pp. 411-416, 2010.

[16] W. B. Edwards, J. C. Gillette, J. M. Thomas, T. R. Derrick, "Internal femoral forces and moments during running: Implications for stress fracture development," Clin. Biomech., vol. 23, no. 10, pp. 1269-1278, 2008.

[17] S. J. G. Taylor, P. S. Walker, J. S. Perry, S. R. Cannon, R. Woledge, "The forces in the distal femur and the knee during walking and other activities measured by telemetry," J. Arthroplasty, vol. 13, no. 4, pp. 428-435, 1998.

[18] K. Haase, G. Rouhi, "Prediction of stress shielding around an orthopedic screw: Using stress and strain energy density as mechanical stimuli," Comput. Biol. Med., vol. 43, no. 11, p. 17481757, 2013.

[19] R. Zdero, S. Shah, P. Goshulak, "Surface Strain Gage Testing of Whole Bones and Implants," Exp. Methods Orthop. Biomech., p. 385, 2017.

[20] P. Bujtár, J. Simonovics, K. Váradi, G. K. B. Sándor, C. M. E. Avery, "The biomechanical aspects of reconstruction for segmental defects of the mandible: A fi nite element study to assess the optimisation of plate and screw factors," J. Cranio-Maxillofacial Surg., vol. 42, no. 6, pp. 855-862, 2014. 